\title{
A Research Agenda for Implementing Augmented Reality in Ab Initio Pilot Training
}

\author{
Birgit Moesl ${ }^{1} \oplus$, Harald Schaffernak ${ }^{1}$, Wolfgang Vorraber $^{1} \oplus$, Reinhard Braunstingl ${ }^{2}$, \\ Thomas Herrele ${ }^{3}$, and loana V. Koglbauer ${ }^{4}$ (]
}

${ }^{1}$ Institute of Engineering and Business Informatics, Graz University of Technology, Austria

${ }^{2}$ Institute of Mechanics, Graz University of Technology, Austria

${ }^{3}$ Aviation Academy Austria GmbH, Neusiedl am See, Austria

${ }^{4}$ Airbus Defence and Space, Manching, Germany

\begin{abstract}
Augmented reality applications have the potential to change the learning experience and outcomes for the next generation of pilots. This study aimed at identifying learning issues related to ab initio flight training and exploring the potential of augmented reality in tackling them. A survey was conducted with 43 pilots (31 men, 12 women) and seven flight instructors (six men, one woman). The results show the contents of the $a b$ initio flight course that were most difficult to learn according to the pilots' and instructors' experience. In addition, the participants assessed the training conditions they experienced. After familiarization with typical use cases of augmented reality, the pilots and flight instructors indicated flight training elements that could benefit from augmented reality. The results are used to specify a research agenda for developing augmented reality applications for future ab initio pilot training.
\end{abstract}

Keywords: ab initio flight training, pilot, flight instructor, augmented reality, training means, synthetic training device

In the past years, based on devices such as HoloLens 2, Google Glass Enterprise Edition 2, Oculus Quest 2, augmented reality (AR) has played an emerging role in different industries. These devices can visualize virtual cues related to the real environment in the field of view of the users. Furthermore, the wireless user experience of this generation of devices simplifies the utilization in different application areas, and has the potential to enable a variety of novel use cases. For example, AR applications have been used in gaming and education because they promote learning, engagement, and enjoyment (Georgiu \& Kyza, 2017).

The Aviation Instructor's Handbook (Federal Aviation Administration [FAA], 2020) mentions that using audio and visual aids can help the learner to be guided and maintain attention and to overcome, for example, communication barriers due to language or cultural differences. Furthermore, it mentions new trends in aviation training and a shift from traditional classrooms to lab-type environments. Miniature electro-optical devices are considered to assist and augment the real situational cues (e.g., by displaying information) that can be seen as AR devices. Although virtual reality (VR) has great potential for flight instruction, this is still considered to be expensive. (FAA, 2020)

Furthermore, the COVID-19 pandemic caused the aviation industry, among others, to rethink already-established methods and existing training standards to meet new hygienic requirements in dealing with training during the pandemic (European Aviation Safety Agency [EASA], 2020). This could pave the way for new use cases such as remote consultation or remote learning, which allows people to work together without a local proximity to each other. EASA (2020, p. 6) mentions in their published guidelines for virtual and distance learning as an example for an equivalent to traditional training "demonstrations, including those supported by demonstration equipment where virtual reality technology can be applied." In the shift to online and distance learning driven by COVID-19, several aspects need to be considered: Content and teaching style should be suitable for the proposed training method, and the access to the necessary equipment or limitations of the available infrastructure need to be considered (EASA, 2020). While the FAA and EASA guidelines refer to virtual reality (VR), the same principles can be applied to AR. Thus, the question of whether to use AR or VR depends on the use case.

AR applications for pilot training have been the focus of recent research (e.g., procedure training, maintenance training operations, remote assistance, etc.; Brown, 2017, 2018, 2019; Schaffernak et al., 2020). Proposed AR applications for pilot training have been interactive checklists, 
manuals with overlaid 3D models or videos, and interactive models of aircraft systems (Brown, 2017). Schaffernak et al. (2020) reported that pilots of both genders expressed preferences for gaming concepts that can be implemented in AR for making learning more interesting and engaging. Pilots with various types of licenses reported that AR could potentially be beneficial for theoretical and procedural training (Schaffernak et al., 2020).

Although research shows that AR-based training means have the potential to improve pilot training, many design questions are still open. Which training contents should be addressed by developing AR-based training means? Can training conditions and accessibility be improved by the AR technology (e.g., remote consultation)? Traditional engineering approaches have been criticized for prioritizing economic benefits and technically interesting problems instead of emphasizing human characteristics and needs (Parasuraman et al., 2000). The present study emphasizes the needs of the learners and aims to gather specific information that is needed for establishing an AR research agenda for $\mathrm{ab}$ initio flight training.

The development of beneficial AR use cases in support of $\mathrm{ab}$ initio pilot training requires a deep understanding and a holistic view of potential issues and gaps in the current pilot education process. Feedback from instructors and pilots is necessary to gain such insights and to specify use cases and guidance in developing AR applications. To our knowledge, no study has yielded a comprehensive research agenda for implementing AR in pilot education. This is typically a complex problem that cannot be easily solved. This study proposes a twofold approach. One approach is to examine the course contents and identify the most difficult parts in pilot training. Additionally, improvement leverages in using AR may already be identified by pilots and instructors who are informed about AR and its typical applications.

This study uses a survey and a standard AR familiarization session, for identifying learning issues and areas of improvement related to the ab initio flight training.

Based on these data, a research agenda for implementing AR in the ab initio pilot training will be specified. This agenda is expected to have a wider applicability in building beneficial AR applications to support pilot education in future.

\section{Method}

\section{Content of the Survey}

The first part of the survey included a detailed list of 57 contents of the ab initio flight training course (see EASA, 2011) for details on the applicable training contents for PPL[A]).
Table 1. Extract from the survey for the category "approach and landing procedures" adopted from EASA (2011)

\begin{tabular}{l}
\hline Flight training content \\
\hline Aerodrome arrival procedures \\
Approach \\
Landing \\
Short-field landing \\
Crosswind landing \\
Flapless landing \\
Approach to landing with idle power \\
Touch and go \\
Go-around from low height \\
Actions after flight \\
Air traffic control (ATC) compliance and radio communication \\
procedures related to this phase
\end{tabular}

The participants were asked to select those contents of the $a b$ initio flight training that were most difficult to learn according to their experience. An extract of the contents that could be selected is listed in Table 1. In addition, after familiarization with standardized, generic AR applications, the $a b$ initio pilots and flight instructors selected from the list of contents flight training elements that could benefit from AR-based training means. The survey contained additional questions regarding: The type of training means and media used during the ab initio course, the impact of the learning and assessment conditions on students' completion of the ab initio course, the most enjoyable parts of the course, and suggested support mechanisms for improving students' performance. Gender aspects were addressed by asking the participants to express their position to the claim "expectations and class standards were the same for men and women" using one of the following response modalities: "yes," or "I have no experience with this issue," or "no." If the participants did not experience the same standards for women and men, they were asked to elaborate the response and explain the issue encountered.

\section{Familiarization With Augmented Reality (AR)}

Before the participants were asked to select the training contents that could benefit from AR-based training means from the survey, they were asked to watch videos showing three different use cases for AR. One was to visualize 3D objects and place them in the environment to get a more holistic picture. Another one was the interaction with a trainer (remote consultation) via an AR device, that is, the trainer sees what the student sees and he or she can, for example, add holographic notes and/or give input by voice. The last case referred to spatial orientation, that is, using visual, augmented cues for navigation purposes (Schaffernak et al., 2020). 


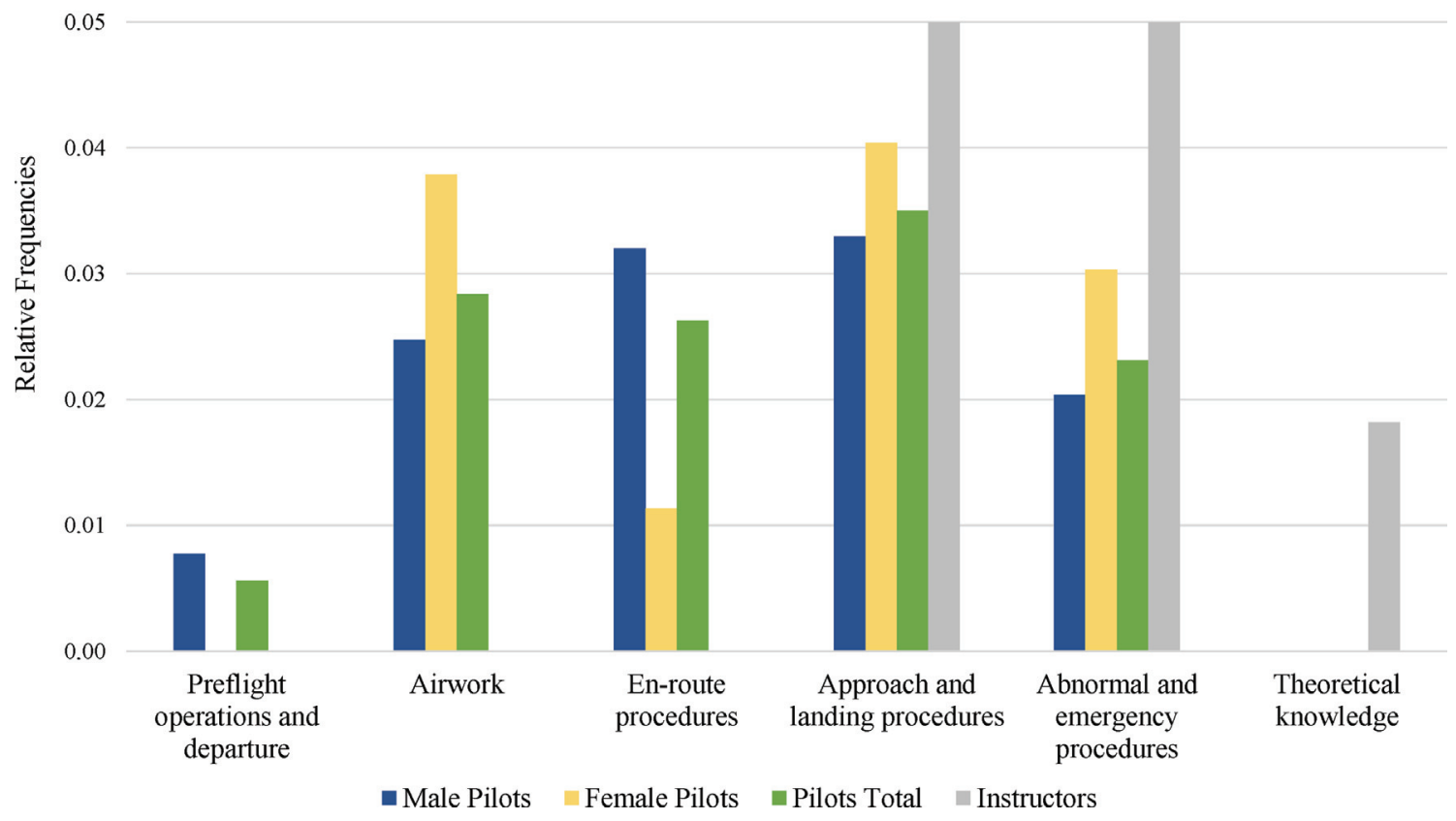

Figure 1. Most difficult contents of the ab initio course.

\section{Data Analysis}

The participants were presented with a list of 57 course elements extracted from the syllabus. For determining the most difficult contents of the syllabus, the participants were asked to select the three most difficult items from a list of 57. For determining the course elements that could benefit from AR-based training means, the participants could select any number of items from the list. Relative frequencies were calculated for data processing. The selected items were assigned to six categories: theoretical knowledge, preflight operations and departure, airwork, enroute procedures, approach and landing procedures, and abnormal and emergency procedures. The number of responses per content category were weighted to counterbalance the varying number of items in different categories. Thus, the number of answers per category was divided by the number of items contained in the category. In addition, the responses were weighted to counterbalance differences in group sizes (e.g., women, men, pilots and instructors). The number of responses per group regarding a particular course element was divided by the total number of responses provided by the individuals included in the respective group (e.g., women, men, instructors). The results are presented descriptively.

\section{Participants}

A sample of $43 \mathrm{PPL}(\mathrm{A})$ pilots participated in the survey. 31 male pilots aged between 20 and 55 years $(M=31.11, M d n=$ 28, $S D=9.54)$ and 12 female pilots aged between 22 and 51 years $(M=33.58, M d n=31.5, S D=9.57)$ participated in the study. In addition, seven PPL(A) instructors were surveyed (six men, one woman). The instructors were aged between 37 and 61 years $(M=47.28, M d n=44, S D=10.14)$. All participants gave their informed consent for the participation in the survey and acknowledged the data protection briefing received according to the procedures of the Graz University of Technology.

\section{Results}

\section{Most Difficult Contents of the Ab Initio Course}

The participants selected the three most difficult course elements from a list. The results are illustrated in Figure 1. Flight instructors reported that approach and landing, abnormal and emergency procedures, and the acquisition 
Table 2. Training means and media experienced during the ab initio flight training course

\begin{tabular}{lcccc}
\hline & $\begin{array}{c}\text { Male } \\
\text { pilots } \\
N=31\end{array}$ & $\begin{array}{c}\text { Female } \\
\text { pilots } \\
N=12\end{array}$ & $\begin{array}{c}\text { Pilots } \\
\text { total } \\
N=43\end{array}$ & $\begin{array}{c}\text { Flight } \\
\text { instructors } \\
N=7\end{array}$ \\
\hline Fype & 31 & 12 & 43 & 7 \\
Real aircraft training & 31 & 12 & 43 & 6 \\
Computer-based training (CBT) & 27 & 8 & 35 & 5 \\
Distance learning courses & 19 & 5 & 24 & 3 \\
Interactive slide presentation & 15 & 5 & 20 & 5 \\
Interactive video presentation & 14 & 4 & 18 & 4 \\
Flight simulator & 11 & 2 & 13 & 5 \\
Others & 7 & 1 & 8 & 2 \\
Interactive tape presentation & 6 & 1 & 7 & 2 \\
\hline
\end{tabular}

of theoretical knowledge were the most difficult parts of the ab initio course encountered by trainees. Pilots reported that learning to apply the procedures for approach and landing, airwork, enroute, abnormal and emergency procedures, preflight operations and departure were the most difficult, with varying relative frequencies of the gender groups.

\section{Parts of the Course Pilots Enjoyed the Most}

Parts of the course female pilots enjoyed the most were practical flight training, cross-country flights (e.g., navigation, realization of the planned route, considering all aspects like weather, airspaces), mountain flying, flying solo, and touch-and-go exercises. Similarly, male pilots enjoyed the most practical flight lessons, cross-country flights, solo sessions, mountain flying (alpine introduction), touch-and-go, stalls, steep-turn exercises, short-field take-offs and landings. Male pilots also enjoyed flying and learning together with other students, and computer-based training (CBT) because they could take enough time for this and it was easy to learn. The instructors' perception matched the pilots' reports. Instructors also thought that students enjoy the most practical flight training, navigation/cross-country flights, and sometimes unusual attitude training. It is noteworthy that some parts of the training that were the most difficult (e.g., touch-and-go are very intensive landing exercises) were also the ones most enjoyed by the students when they mastered them.

\section{Training Means and Media}

As Table 2 shows, formal classroom instruction and real aircraft training were the most frequent training means used in the ab initio course, followed by CBT and distance learning courses. A number of pilots and instructors reported the use of slide and video presentations as well as flight simulation. Only a few pilots and instructors reported the use of tape presentations. Tape, slide, and video presentations in the classroom are interactive when used to animate learners in collaboration, verbal interaction, or manipulation of the training means as compared with one-way communication by the instructor. Other training means reported were bilateral "questions and answers" sessions on students' request, books, videos from YouTube, self-study, meetings on Skype for language proficiency, and radio communication and demonstrations of aircraft parts in the hangar and during maintenance.

\section{Impact of the Learning and Assessment Conditions on Students' Completion of the Course}

None of the instructors reported difficulties of the student pilots with the learning conditions during the course. However, $45.45 \%$ of female and $20.9 \%$ of male pilots reported that the learning conditions made it difficult for some students to complete learning activities. Difficulties mentioned by women were teaching style, availability of instructors, finding dates for classroom instructions, and the use of non-standardized checklists. Men had issues with availability of instructors, the balance between CBT and classroom instruction, with some computer tools that were not explained enough, or the coordination of theoretical instruction and progress checks. Regarding assessment conditions, the results show that $25 \%$ of instructors considered that these created difficulties for some students in completing the assessment activities. However, $75 \%$ of instructors and $100 \%$ of pilots considered that the assessment conditions did not influence students' ability to complete the examinations.

\section{Suggested Support Mechanisms for Improving the Performance/Results of the Students}

Female pilots suggested the following support for improving the learning performance: different ways to explain and more precise feedback, clear communication of learning objectives, explanation of theory directly on the aircraft (e.g., instrumentation), use of standardized procedures and checklists, less paperwork, and more opportunity for airwork. Male pilots proposed the following support for improving the learning performance: more instructors who can guide students through the training, informing students about the next steps, peer support and shared 


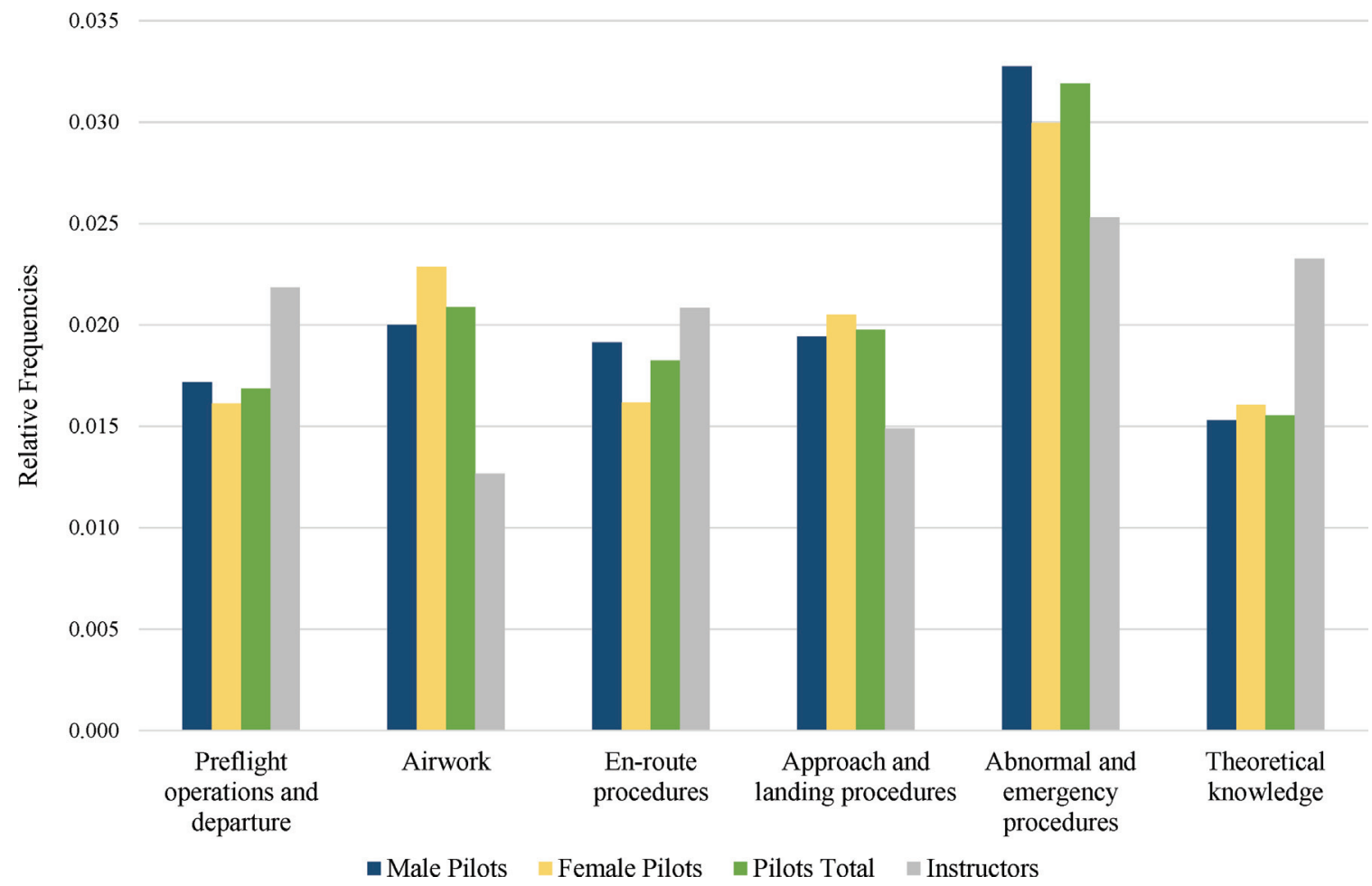

Figure 2. Contents of the ab initio course that were considered to benefit from augmented reality training means.

experience, and availability of simulator training. Instructors indicated that more time to learn could help improve students' performance.

\section{Similarity of Standards and Expectations for Women and Men}

All instructors reported that expectations and class standards were the same for men and women. Overall, $67.7 \%$ of male pilots also considered that expectations and class standards were the same for men and women, and 32.3\% of male pilots stated having no experience with this aspect. In total, $58.3 \%$ of female pilots reported that expectations and class standards were the same for both genders and $16.7 \%$ of female pilots stated having no experience with this. However, $25 \%$ of female pilots acknowledged a difference. Female pilots recalled that some instructors unintentionally made a difference in explanations to women, especially with more technical or practical parts. Some female students felt they needed to address the instructor's comments such as "Why young girls like to fly." A female pilot noted that: "Men start to learn flying because they are said to be technical natives, women need to explain why they are on an airfield because they are said to be technical immigrants. Therefore, women lose time for learning and discussing the interesting technical things."

\section{Assessment of the Course Content That Could Benefit From AR-Based Training Means}

As illustrated in Figure 2, the pilots and instructors considered that every area of the ab initio course could benefit from AR-based training means. However, the highest relative frequency was noticed for abnormal and emergency procedures.

\section{Discussion}

Based on results of this study and relevant AR developments in flight training (e.g., procedure training, maintenance training operations, remote assistance, etc.; Brown, 2017, 2018, 2019; EASA, 2020; Schaffernak et al., 2020) we propose an agenda for future research on AR in the ab initio pilot training that addresses the course content, learner support, and learning conditions. The training means and media used for flight training evolved over time and they are intrinsically related to the learning conditions and outcomes. The results show that instructors and pilots alike experienced a wide range of traditional training means and media during the ab initio flight course. The aim of this exploratory study was to specify a research agenda for 
implementing AR in the ab initio flight training based on data about learning issues and areas of improvement from the perspective of both pilots and instructors. This agenda is expected to have a wider applicability in developing AR applications to support future pilot education.

\section{AR Applications Related to the Course Content}

Although the surveyed pilots and instructors considered that all course contents could benefit from AR, the additional results can be used to guide and set priorities in the design and evaluation of AR-based training means. Data on course contents that students enjoyed the most are interesting, but they did not influence the priorities for this AR research agenda. Thus, priorities are set based on the most difficult training contents related to the ab initio course. The survey identified the categories, but participants were not asked to propose AR contents. Generic AR-based training means that could be used to address the contents considered to be most difficult are discussed here.

The results show that approach and landing contents (Figure 1) were considered the most difficult to learn by instructors and pilots of both genders. These are at the top of the research agenda. For practical exercises in the landing phase and in the traffic pattern, AR might support the learning process by giving additional information to the student. AR-based applications could be used to augment visual cues and help students navigate when approaching an airport, or to help them estimate their flight path relative to the runway. Traditionally, instructors use verbal communication to direct students' attention to a multitude of visual cues that need to be managed timely and correctly for a correct approach and landing. As things happen very quickly, traditional instructions are more focused on what went wrong during these exercises and on providing suitable clues. With AR cues, ab initio student pilots could develop correct mental models early in training and training could be more efficient. Further research should focus on which type of additional information provided by AR devices can help to improve difficult to learn exercises and how this can be achieved.

Second on the research agenda is the category of abnormal and emergency procedures. This includes some of the most difficult learning contents, and was also considered to benefit from AR-based training means by instructors and pilots of both genders. The course contents in this category are simulated emergencies, engine failure, as well as simulated forced and precautionary landings. AR could be used to simulate emergency conditions (e.g., smoke, fire), but also to aid students in overlaying the approach and landing patterns of airports as required by simulated precautionary and forced approaches and landings.

Although instructors did not consider airwork difficult to learn, this is still relevant for the agenda, because pilots of both genders rated some of the most difficult elements to be in this category: turns, climbing, descending, straight and level flight with speed changes, and stalls. AR-based training means could help students identify the visual cues necessary for estimating the pitch, roll, and yaw angles relative to the natural horizon, in a similar way as the artificial horizon instrument does. The ability to "read" such cues relative to the natural horizon is essential for visual flight rules (VFR) flight that is specific for ab initio flight training and requires the pilots to look outside most of the time. Previous research used hardware sighting devices as training aids, but concluded that these would need further development (Bauer et al., 2019). AR could be used as a training aid for simulator training.

Interestingly, en route procedures were considered most difficult by a number of pilots, but not by instructors. Despite differences between instructors and pilots, this category is on the agenda. En route procedures consist of elements such as navigation (e.g., map reading, use of flight instruments, and radio navigation aids), log keeping, flight management (checks, fuel systems, and carburetor icing, etc.), and diversion to an alternative aerodrome. Since navigation support is one of the typical cross-domain AR applications, this could be used for ab initio pilot training, either in connection with a flight simulator or as stand-alone.

Only few male pilots considered pre-flight operations and departures as the most difficult. However, instructors and pilots of both genders considered that AR-based training means could be beneficial. Indeed, interesting AR applications could be developed to support teaching of contents such as aircraft inspection and servicing, navigation during taxi and departure. Some of the hands-on training (e.g., outside check, cabin training, emergency equipment location) could be improved significantly by AR, as it offers insights that are impossible in the real world (e.g., cut view through the aircraft). Further studies should identify the most suitable methods for enhancing system learning via AR. The use case of AR-based procedure training including checklists in connection with a cockpit simulator has already been addressed (Brown, 2018).

Although only instructors identified theoretical contents to be some of the most difficult elements of the ab initio flight course, both the pilots and the instructors considered that AR-based training aids for theoretical knowledge could be useful. Generally, AR cues are expected to complement theoretical and practical training means and to support learners in developing mental models and models of action. As Brown (2017) noted, AR applications can be developed and used to bridge the gap between theoretical and 
practical instruction. In addition, Brown (2018) proposed AR applications for theoretical contents such as meteorology and engine systems. Furthermore, synthetic training devices could use augmented cues of key situational awareness elements and assist learners' selective attention during visual flight. However, future research needs to provide evidence for the effects of AR applications on training effectiveness as compared to traditional training means. In addition, skills learnt with AR should be transferable to flight without augmented cues. It is not the purpose of a training aid that students become dependent on them. Instead, AR should support students in developing the skills and mental models necessary for flight according to VFR rules. AR enforces the immersion of the training experience and, thus, can potentially improve the training effectiveness.

\section{AR Features to Support Students' Learning Performance}

Learning support required by female pilots identified in this study (e.g., alternative ways to explain, more precise feedback, explanation of theory directly on the aircraft) could be developed by seizing technical opportunities provided by AR devices. Virtual cues that are projected directly on the real aircraft could be used to explain theoretical and technical concepts.

Furthermore, selected gaming concepts and individual forms of real-time feedback projected directly into the line of sight of participants could be realized in a gendersensitive way based on AR, as described by Schaffernak et al. (2020). Peer support and shared experience that were addressed by male pilots can be enabled by AR-supported virtual collaborative meetings and remote consultations. AR-supported meetings can benefit from new possibilities to collaborate. AR gives the possibility to overcome the barrier of different locations, to increase the availability of instructors, and to do one-to-one training (e.g., procedure training). In addition to communication opportunities as offered by Skype, Zoom, and others, AR enables the instructor to interact with the environment of the student and place holographic elements. Using AR, the participants can discuss and interact with shared 3D objects (e.g., disassemble a technical component). They can also move in the virtual space and interact as avatars.

\section{Impact of AR on the Learning and Assessment Conditions}

Furthermore, future research of $\mathrm{AR}$ in flight training should address opportunities to improve the learning conditions (e.g., teaching style, availability of instructors, finding dates for classroom instructions, or the coordination of theoretical instruction and progress checks). Various levels of immersion may be used to support virtual collaboration ranging from lightweight/minor virtual annotations created, for example, during remote consultations, to shared collaboration on complex virtual objects (e.g., virtual model of an engine) in a virtual shared space. These forms of ARsupported collaboration enable teachers and learners to overcome spatial barriers and consequently ease scheduling for teaching and training sessions while fostering flexibility in scheduling and compliance with current COVID-19related restrictions. In addition, students' assessments (e.g., progress checks) and instructors' interventions could benefit from particular AR-based training means. For example, if AR could help instructors notice the difference between students' cognitive skills (e.g., looking at the right cues, using an accurate mental model for the interpretation of the cues) versus the development of psychomotor skills of controlling the aircraft. Current developments in AR end devices show that various sensors and functions are converging into single devices (e.g., HoloLens2 provides features such as eye-tracking and hand-tracking in addition to AR functionality) and thereby facilitate improved AR experiences. Thus, research on the impact of AR on the learning and assessment conditions is part of the proposed agenda.

\section{Instructor Training}

On the basis the results of this study, we propose improvements for the education of flight instructors to include AR teaching means, information about learners' difficulties regarding content and learning conditions, and information on gender diversity in flight training. New features of AR devices such as eye-tracking could be very useful for instructors, too. Therefore, research on developing instructors' AR skills is part of the AR research agenda proposed here.

\section{Limitations}

The results of this exploratory study give an indication of current limitations and future opportunities for improving $\mathrm{ab}$ initio flight training. Establishing the research agenda is the first phase of an ongoing research program of the Graz University of Technology in collaboration with Approved Training Organizations. For this reason, learning objectives and the specification of AR applications to be developed were not addressed in the survey, but need to be addressed in future workshops and use case studies. Future studies could also include a greater number of participants and a research design to address different experience levels and ages. Furthermore, participants with 
various cultural backgrounds could be included because they might have different needs and might interact differently with collaborative remote learning environments. These aspects could not be covered by the present study. In addition, the technical capabilities of AR are in continuous development and, thus, current limitations of AR devices such as a narrow field of view, weight, calibration issues, and high costs may be improved in the future. Furthermore, new devices (e.g., in the form of wearables) and applications will change the ascribed potential in the technology; hence, a regular review of the research agenda for AR applications in flight training is recommended.

\section{Conclusion}

This study proposes a research agenda for implementing AR-based training means in ab initio pilot training. The agenda takes into consideration the most difficult training contents, preferences of pilots and instructors, learning support specified by pilots, learning and assessment conditions, as well as instructors' AR-related knowledge and skills. The results show that instructors and pilots of both genders consider that AR has the potential to improve pilot training. In addition, this study identifies the most difficult course contents and conditions that could be addressed at least partially by using AR applications. The research agenda for implementation of AR in the ab initio flight training proposed here is important because the engineering process can be guided to prioritize AR applications that address learner needs while considering gender diversity in an inclusive way. In comparison, traditional engineering approaches have been criticized for prioritizing economic benefits and technically interesting problems (Parasuraman et al., 2000). Such research is necessary, since alternative and remote training methods are the focus of training organizations and regulatory agencies. The agenda proposed here should be reviewed and updated since AR technology is progressing and specific limitations and challenges with AR are changing.

\section{References}

Bauer, S., Braunstingl, R., Riesel, M., \& Koglbauer, I. (2019). Improving the method for upset recovery training of $a b$ initio student pilots in simulated and real flight. In M. Schwarz, J. Lasry, G. N. Schnücker, \& H. Becherstorfer (Eds.), Proceedings of the 33rd Conference of the European Association for Aviation Psychology (pp. 167-179). EAAP.

Brown, L. (2017). The next generation classroom: Transforming aviation training with augmented reality. In NTAS (Ed.), Proceedings of the National Training Aircraft Symposium (NTAS) (pp. 1-25). Embry-Riddle Aeronautical University, Daytona Beach, FL, USA, 14-16 August 2017. https://commons.erau. edu/ntas/2017/presentations/40/?utm_source=commons.erau.
edu\%2Fntas\%2F2017\%2Fpresentations\%2F40\&utm_medium= PDF\&utm_campaign=PDFCoverPages

Brown, L. (2018). Holographic micro-simulations to enhance aviation training with mixed reality. Presentation at the National Training Aircraft Symposium (NTAS), Embry-Riddle Aeronautical University, Daytona Beach, Florida, USA. https://commons. erau.edu/ntas/2018/presentations/1

Brown, L. (2019). Augmented reality in international pilot training to meet training demands. Instructional Development Grants, Western Michigan University. https://scholarworks.wmich. edu/instructional-development-grants/1

European Aviation Safety Agency. (2011). Acceptable means of compliance and 1 guidance material to Part-FCL. https://www. easa.europa.eu/sites/default/files/dfu/AMC\%20and\%20GM\% 20to\%20Part-FCL.pdf

European Aviation Safety Agency. (2020). Guidance for allowing virtual classroom instruction and distance learning. Guidelines in relation to the COVID-19 pandemic. Issue No. 5. https://www.easa.europa. eu/document-library/general-publications/guidance-allowingvirtual-classroom-instruction-and-distance

Federal Aviation Administration. (2020). Aviation instructor's handbook. FAA-H-8083-9B. US Department of Transportation, Federal Aviation Administration, Flight Standards Service.

Georgiu, Y., \& Kyza, E. A. (2017). The development and validation of the ARI questionnaire: An instrument for measuring immersion in location-based augmented reality settings. International Journal of Human-Computer Studies, 98, 24-37. https://doi. org/10.1016/j.ijhcs.2016.09.014

Parasuraman, R., Sheridan, T. B., \& Wickens, C. D. (2000). A model for types and levels of human interaction with automation. IEEE Transactions on Systems, Man, and Cybernetics - Part A: Systems and Humans, 30(3), 286-297. https://doi.org/10.1109/3468.844354

Schaffernak, H., Moesl, B., Vorraber, W., \& Koglbauer, I. (2020). Potential augmented reality application areas for pilot education: An exploratory study. Educational Sciences, 10, Article 86. https://doi.org/10.3390/educsci10040086

\section{History}

Received November 6, 2020

Revision received February 17, 2021

Accepted August 11, 2021

Published online November 18, 2021

\section{Acknowledgments}

The authors gratefully acknowledge all the pilots who completed the survey.

\section{Funding}

This research was funded by the Austrian Federal Ministry for Climate Action, Environment, Energy, Mobility, Innovation and Technology, and the Austrian Research Promotion Agency, FEMtech Program “Talent,” grant number 866702.

\section{ORCID}

Birgit Moesl

(iD) https://orcid.org/0000-0002-9770-6186

Harald Schaffernak

(iD) https://orcid.org/0000-0002-6673-618X

Wolfgang Vorraber

(iD) https://orcid.org/0000-0002-1550-2279

loana Koglbauer

(D) https://orcid.org/0000-0002-1682-6304 


\section{Birgit Moesl}

Institute of Engineering and Business Informatics

Graz University of Technology

Kopernikusgasse 24/III

8010 Graz

Austria

birgit.moesl@tugraz.at

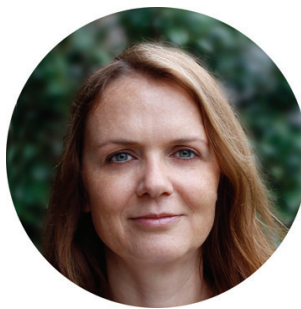

Birgit Moesl is a research assistant and PhD student at the Institute of Engineering and Business Informatics at the Graz University of Technology, Austria. Her research interest is in sociotechnical systems, responsible research, and innovation and gender studies. In addition, she is an active pilot.

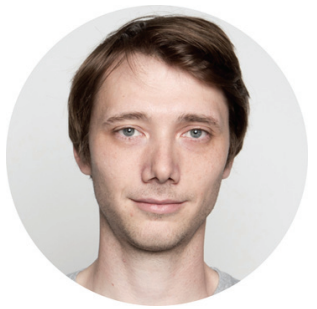

Harald Schaffernak is a PhD student at Graz University of Technology - Institute of Engineering and Business Informatics. Furthermore, he is co-founder of Guid.New GmbH, an SME software engineering company. His research interest is in the area of software quality and augmented reality.

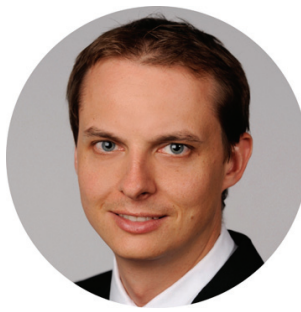

Wolfgang Vorraber is an associate professor at Graz University of Technology, Austria. His research interests include business information systems engineering and sustainable service design with a special focus on production, public safety, health care, and aviation. Wolfgang received a $\mathrm{PhD}$ in engineering economics and management.

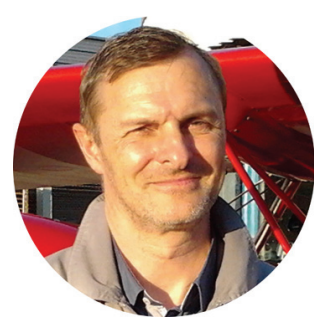

Reinhard Braunstingl received a $\mathrm{PhD}$ degree in mechanical engineering from Graz University of Technology, Austria, in 1991. He is a professor with the Graz University of Technology, as well as the head of the research platform Flight Simulation. In addition, he is an experienced pilot, flight instructor, and flight examiner.

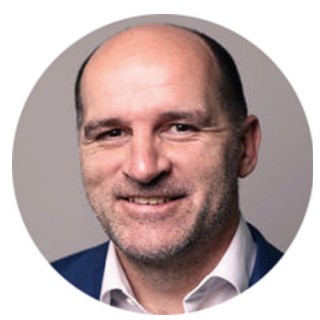

Thomas Herrele has been airline pilot since 1995, a flight instructor, and was CEO of an aviation training organization in Austria. He received his Master of Engineering (MEng) in Aviation Safety Traffic Accident Research from the Graz University of Technology, Austria.

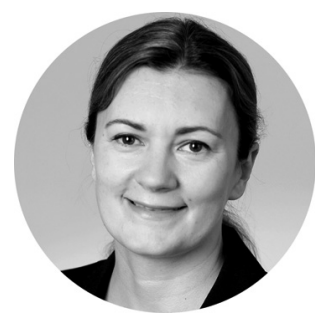

Ioana Koglbauer is an aviation psychologist and human factors expert. She received her $\mathrm{PhD}$ and habilitation in psychology from the University of Graz, Austria, and is an active pilot. She was a researcher and project manager at TU Graz, Austria, and is currently affiliated with Airbus Defence and Space, Manching, Germany. 